\title{
Application of voxel phantoms to study the influence of the heterogeneous distribution of actinides in lungs on in vivo counting using animal experiments
}

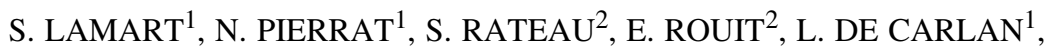
N. DUDOIGNON ${ }^{3}$, M. BOTTLAENDER ${ }^{4}$, A. VAN DER MEEREN ${ }^{2}$, D. FRANCK $^{1}$

(Manuscript received 24 May 2006, accepted 11 December 2006)

ABSTRACT As part of the improvement of calibration techniques for in vivo counting, the Laboratory of Internal Dose Assessment of IRSN has developed a computer tool, "OEDIPE", to model internal contamination in voxel phantoms, to simulate in vivo counting and to calculate internal dose. This software was used to model the real distribution of activity in the lungs of a baboon analyzed in the Laboratory of Radiotoxicology of CEA. This experiment provided the opportunity to study the influence of the heterogeneity of lung retention on the in vivo counting and to quantify its effect on the assessment of activity by comparison with a simulated homogeneous retention of the same total activity. The results show that the numerical simulation can be a relevant tool to reveal the heterogeneity of lung retention, allowing a determination of calibration factors adapted to heterogeneous contaminations that would be impossible by standard calibration with physical anthropomorphic phantoms.

Keywords: Lung counting / Monte Carlo method / heterogeneous contamination model / animal experiment

RÉSUMÉ Application des fantômes numériques voxélisés à l'étude de l'influence sur la mesure anthroporadiamétrique des distributions hétérogènes des actinides dans les poumons à l'aide de mesures sur animal.

Dans le cadre de l'amélioration des techniques d'étalonnage en anthroporadiamétrie, le Laboratoire d'Évaluation de la Dose Interne de l'IRSN a développé un outil numérique, « EDIPE », pour modéliser la contamination interne dans des fantômes numériques voxélisés, simuler la mesure anthroporadiamétrique et estimer la dose interne. Ce logiciel a été utilisé pour modéliser une distribution d'activité réaliste au niveau pulmonaire, obtenue chez un babouin au Laboratoire de radiotoxicologie du CEA. Cette expérience a été l'occasion d'étudier l'influence des hétérogénéités de rétention pulmonaires sur la mesure in vivo et de comparer, par simulation, la mesure qui en résulte à celle d'une contamination homogène de même activité totale dans les poumons. Les résultats montrent que la simulation numérique peut être un outil très pertinent pour mettre en évidence les hétérogénéités de

\footnotetext{
IRSN, Laboratoire d'Évaluation de la Dose Interne, DRPH/SDI/LEDI, B.P. 17, 92262 Fontenay-aux-Roses, France.

CEA, Laboratoire de Radiotoxicologie, DSV/DRR/SRCA/LRT, B.P. 12, 91680 Bruyères-le-Châtel, France.

IRSN, Laboratoire de Radiopathologie, DRPH/SRBE/LRPAT, B P. 17, 92262 Fontenay-aux-Roses, France.

CEA, Service Hospitalier Frédéric Joliot, 4, place du général Leclerc, 91400 Orsay, France.
} 
rétention, permettant une meilleure détermination des coefficients d'étalonnage dans des cas de contamination hétérogènes ; ce qui serait impossible à réaliser par la méthode standard d'étalonnage avec des fantômes physiques anthropomorphes.

\section{Introduction}

The calibration of the in vivo counting systems, used to assess the retention of activity in the whole body or in a specific organ, is usually performed with physical anthropomorphic phantoms. Although significant efforts have been made to improve these phantoms, especially for lung counting, each of them represent a single average morphology and usually contains a uniform distribution of activity within the tissue substitute. This rough representation of the actual contamination in a specific human body leads to large uncertainties in the assessment of activity and dose. Consequently, some assumptions have to be made to correct the calibration factors derived from physical phantoms in order to estimate more realistic calibration efficiencies applicable to a given subject. The main assumptions are related to the chest wall thickness (CWT), to the adipose content and to the localization of the activity. These corrections are especially important for the measurement of actinides due to the absorption of low-energy photons in the chest wall tissues.

It was therefore of great interest to develop a method which would be more sensitive to these types of variability in order to improve calibration. Techniques using numerical phantoms (Mallett et al., 1995; Hickman and Firpo, 1997; Ishikawa and Uchiyama, 1997) associated with Monte Carlo calculation methods (Hughes et al., 1997; Briesmeister, 2000) have thus been developed for the calibration of counting systems. Taking advantage of the recent improvements of image-processing software, we extended such investigations to the creation of numerical anthropomorphic phantoms based on personal anatomical data acquired by computed tomography (CT) or magnetic resonance imaging (MRI). Then a friendly Graphical User Interface was developed using person-specific computational phantoms in association with the MCNP calculation code. This interface called OEDIPE (French acronym for "tool for personalized internal dose assessment") allows in vivo measurement to be simulated for an improved calibration (Franck et al., 2001; Borisov et al., 2002, 2005; de Carlan, 2004; Aubineau-Laniece et al., 2005a, 2005b).

Using this numerical tool, a first approach to study the influence of the activity distribution in the lungs on the calibration factor has been explored. Since very few data related to the geometric pattern of inhaled particles deposited in the lungs are available, a study was initiated in the frame of collaboration between the Laboratory of Internal Dose Assessment (LEDI) of IRSN and the Laboratory of 
RadioToxicology (LRT) of CEA which is specialized in biokinetic studies. The objectives of this study were to model an actual contamination by actinides heterogeneously distributed in the pulmonary lobes of a baboon; and to compare the result of a simulation of the lung measurement taking this heterogeneous distribution into account with those of a simulation under the usual assumption of a homogeneous distribution of the inhaled material in the whole lung. This comparison was performed using EDIPE which can simulate almost any distribution of source activity.

\section{CEDIPE tool}

EDIPE is based on a Graphical User Interface developed under the IDL environment (Franck et al., 2001; Borisov et al., 2002, 2005; de Carlan, 2004; Aubineau-Laniece et al., 2005a, 2005b; Pierrat et al., 2005; de Carlan et al., 2005). The software's main goals are the fast creation of voxel phantoms and the automatic writing of the input file for the Monte Carlo calculation code used to simulate particle transport through the matter (MCNP or MCNPX, Hughes et al., 1997; Briesmeister, 2000). The software comprises several modules that are described below. Several data types are required for the simulation. The first data type consists in anatomical images from CT or MRI where the organs of interest are segmented (outlined) by the grey-level method or through a semi-automatic method using the external software Dosigray ${ }^{\odot}$. The segmentation is followed by the association of each voxel with the density value and the elementary composition of the tissue it belongs to, as specified by ICRU (1989). The second required data type relates to the contaminating radionuclides and to their spatial distribution which can be detailed at the level of organs or fractions of organs. The last required data type is the nature of the output data requested by the user and referred to as "tally" in the MCNP or MCNPX code. This can be the photon spectrum in one or several detector(s) whose type(s) and position(s) with respect to the phantom have then to be specified, or the dose distribution in a specific region of the phantom.

\section{Study of a real lung contamination in an animal model}

\subsection{Experimental method}

The experimental protocol described below was performed in agreement with the French regulations for animal experimentation (Ministry of Agriculture Act. $\mathrm{N}^{\circ}$ 87-848 October 19th, 1987 modified May 19th, 2001). 


\section{TABLE I}

Isotopic composition of a MOX compound of type MIMAS 4. Composition isotopique d'un composé MOX de type MIMAS 4.

\begin{tabular}{lccccccc}
\hline MIMAS & ${ }^{238} \mathrm{Pu}$ & ${ }^{239} \mathrm{Pu}$ & ${ }^{240} \mathrm{Pu}$ & ${ }^{241} \mathrm{Pu}$ & ${ }^{242} \mathrm{Pu}$ & ${ }^{241} \mathrm{Am}$ & Total \\
\hline Emitter & $\alpha$ & $\alpha$ & $\alpha$ & $\alpha$ & $\alpha$ & $\alpha$ & \\
$\%$ activity $\alpha$ & $64.5 \%$ & $7.62 \%$ & $12.3 \%$ & $0.03 \%$ & $0.05 \%$ & $15.6 \%$ & $100 \%$ \\
$\%$ mass & $1.78 \%$ & $57.9 \%$ & $25.5 \%$ & $6.61 \%$ & $6.12 \%$ & $2.17 \%$ & $100 \%$ \\
\hline
\end{tabular}

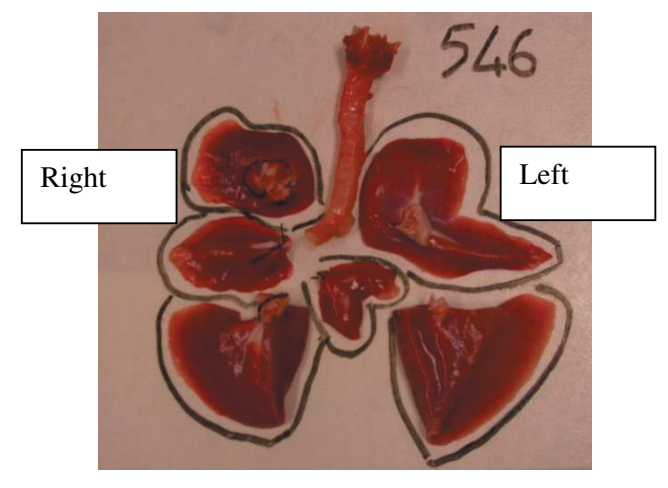

(a)

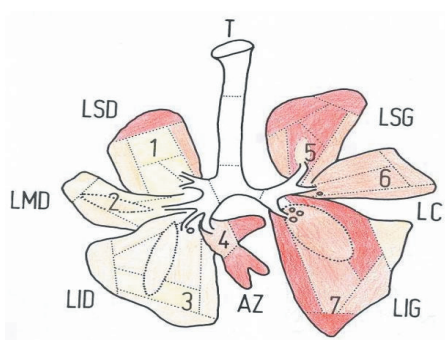

$>15 \mathrm{MBq} / \mathrm{kg}$

10 to $15 \mathrm{MBq} / \mathrm{kg}$

5 to $10 \mathrm{MBq} / \mathrm{kg}$

0.5 to $5 \mathrm{MBq} / \mathrm{kg}$

$<0.5 \mathrm{MBq} / \mathrm{kg}$

(b)

Figure 1 - (a) Pulmonary lobes of the baboon; (b) dissection plan and mass activities measured in the parts of the lobes after euthanasia.

(a) Lobes pulmonaires du babouin ; (b) schéma de dissection et activités massiques mesurées dans les parties des lobes après euthanasie.

An $8 \mathrm{~kg}$ female baboon (Papio papio) was contaminated by acute intra-tracheal instillation of MOX aerosol using specific devices of the LRT (Lataillade et al., 1995). The initial activity deposited in the lung was $800 \mathrm{kBq}$ of MOX aerosol of type MIMAS $4\left(\right.$ AMAD $=3.5 \mu \mathrm{m}$; specific activity $\left.=12.3 \mathrm{GBq} \mathrm{kg}^{-1}\right)$, which isotopic composition is presented in Table I.

An in vivo lung measurement was performed every 2-3 days until the euthanasia that was performed one month after contamination.

The lungs were then collected and the : superior (LSD), middle (LMD), inferior (LID) and accessory (azygos, AZ) lobes of the right lung as well as the superior (LSG), central (LCG) and inferior (LIG) lobes of the left lung (Prot, 1994) were separated (Fig. 1). 
TABLE II

Measured activities in the different pulmonary lobes of the baboon. The figures in parentheses are the minimum and maximum values measured with the proportional counter and the $\mathrm{NaI}(\mathrm{Tl})$ detector.

Activités mesurées dans les différents lobes pulmonaires du babouin. Les chiffres entre parenthèses sont les valeurs minimales et maximales obtenues avec le compteur proportionnel et le détecteur $\mathrm{NaI}(\mathrm{Tl})$.

\begin{tabular}{lcc}
\hline & Number of pieces in each lobe & Measured activity (kBq) \\
\hline LSD & 6 & $34.1(33.3-34.8)$ \\
LMD & 5 & $24.1(23.9-24.3)$ \\
LID & 7 & $96.9(95.6-98.2)$ \\
AZ & 3 & $39.3(38.5-40.2)$ \\
Total for right lobes & & 194 \\
LSG & 7 & $142(141-143)$ \\
LCG & 5 & $50.6(49.8-51.3)$ \\
LIG & 8 & $322(320-325)$ \\
Total for left lobes & & 515 \\
Total for the whole lungs & & 710 \\
\hline
\end{tabular}

Each of the 7 lobes was then cut up, according to the dissection plan of Figure 1b, into pieces that were weighed and measured by photon spectrometry with two different detectors: a proportional counter and a $\mathrm{NaI}(\mathrm{Tl})$ detector.

\subsection{Experimental results}

The total activity of all alpha emitters in each lobe is presented in Table II as the average of the results from the two detectors.

This contamination appears very heterogeneous as there are important variations of mass activity from one lobe to another (Fig. 1b). Moreover, more than $70 \%$ of the total activity is located in the left lobes.

\section{Comparison of the simulated measurements of heterogeneous and homogeneous lung contaminations}

In order to compare the measurements resulting from a realistic contamination in the lungs and from a hypothetical homogeneous contamination in the whole lungs, the experimental conditions were reproduced through simulation: a numerical phantom of the baboon was reconstructed from CT-scan images. The different 


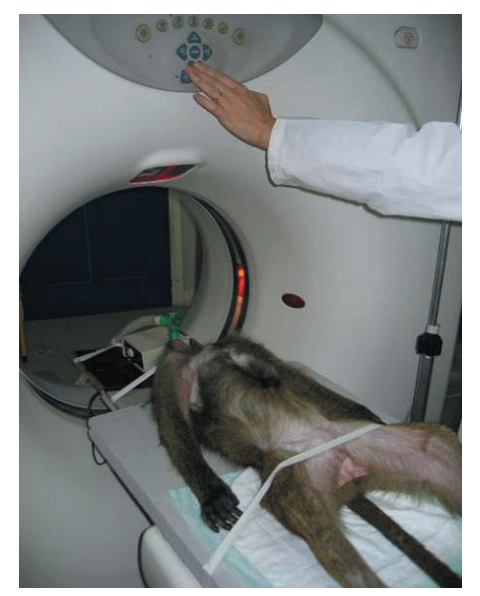

Figure 2-Acquisition of CT-scan images of the baboon under general anaesthesia.

Acquisition des images de tomographie par rayons $X$ du babouin sous anesthésie générale.

pulmonary lobes were segmented on the phantom in order to reproduce the distribution of activity derived from the experimental data.

\subsection{Numerical method}

\subsubsection{Acquisition of CT-scan images}

Due to the MOX contamination, no CT-scan of the baboon could be performed before euthanasia. This exam was therefore performed on a baboon of similar weight $(9 \mathrm{~kg})$ under general anaesthesia at the Radiotherapy Centre of the École Vétérinaire de Maisons-Alfort (Fig. 2). 137 2D images of $5 \mathrm{~mm}$ thick were acquired to cover the whole body of the baboon. The resolution was $512 \times 512$ pixels, corresponding to pixels of $0.7 \times 0.7 \mathrm{~mm}^{2}$. Only the 37 images covering the thorax were used in this study.

\subsubsection{Numerical reconstruction of the baboon thorax phantom}

The same procedure as described in paragraph 2 was used to reconstruct the numerical phantom: the soft tissues, the bones, the spinal cord and each of the 7 pulmonary lobes were segmented using Dosigray ${ }^{\circledR}$ software (Fig. 3).

As the sub-parts of each lobe are not anatomically distinguishable on an axial slice of the voxel phantom, they could not be segmented. The segmentation of the lobes, presented in Figure 4 was not perfect due to the overlaps between them but it was considered sufficiently accurate for the purpose of this study (comparison between two simulations). 

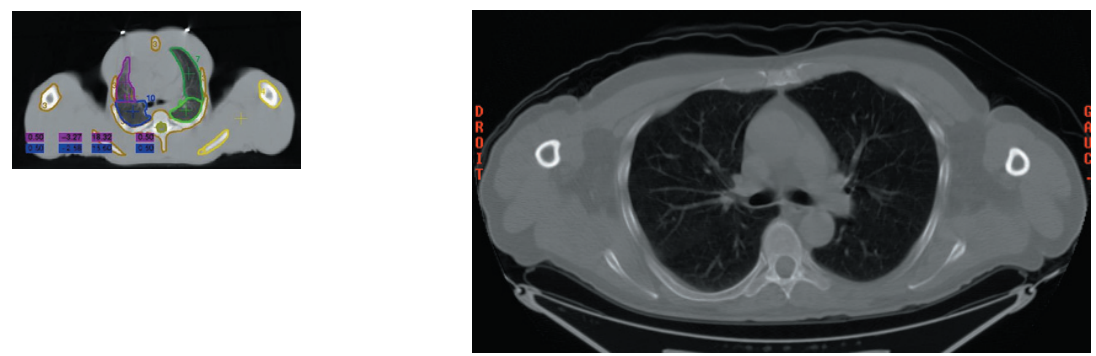

Figure 3-Segmentation of a CT-scan thoracic slice of the baboon with Dosigray ${ }^{\odot}$ software and comparison with a CT-scan thoracic slice of a human being $(178 \mathrm{~cm}, 73 \mathrm{~kg})$.

Segmentation d'une coupe thoracique scanner du babouin avec le logiciel Dosigray ${ }^{\circledR}$ et comparaison avec une coupe thoracique scanner d'un être humain $(178 \mathrm{~cm}, 73 \mathrm{~kg})$.

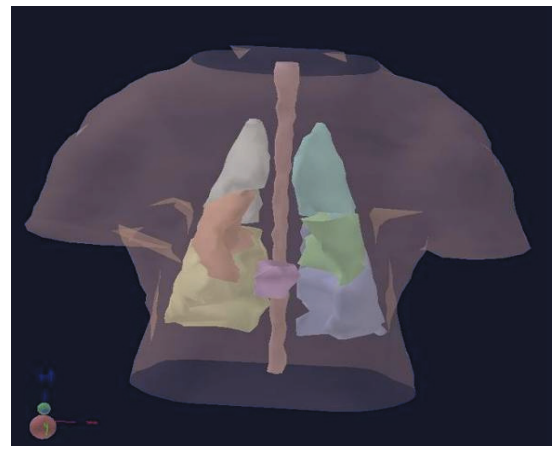

Figure 4-3D visualization of the lungs and spinal cord of the baboon phantom with Dosigray ${ }^{\circledR}$ software. Soft tissues are represented as semi-transparent. Visualisation en $3 D$ des poumons et de la moëlle épinière du fantôme numérique du babouin avec le logiciel Dosigray $^{\circledR}$. Les tissus mous sont représentés en semi-transparent.

The major differences in thoracic morphology between a baboon and a human being is shown on tomographic slices in Figure 3: the thoracic cage of a baboon is narrower along the mediolateral axis and wider along the anteroposterior axis than the one of a human being.

The contours of the tissues were imported into OEDIPE and the numerical phantom of the baboon was reconstructed. Each tissue of the phantom was assumed to have the same density and composition as the corresponding human tissue (ICRU, 1989).

\subsubsection{Definition of lung sources}

In order to study the influence on the in vivo lung measurement of the heterogeneous distribution of activity in lungs, two source geometries were considered:

- a homogeneous distribution of activity in the whole lungs, 


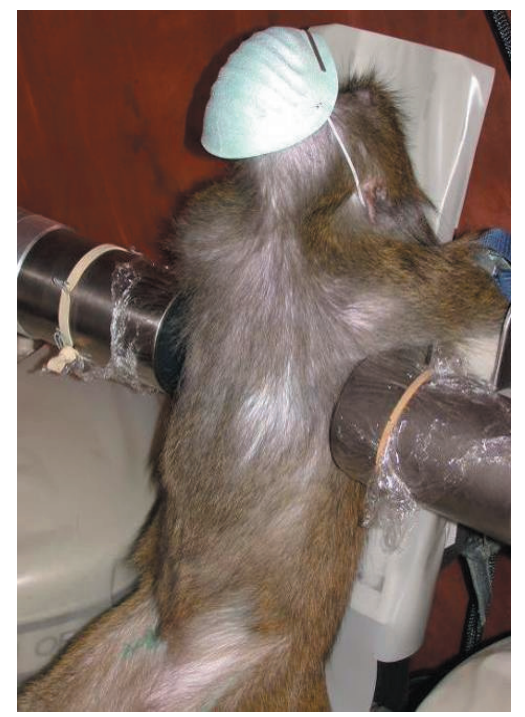

Figure 5-In vivo lung measurement system dedicated to anaesthetized non human primates at the LRT.

Système d'anthroporadiamétrie pulmonaire du LRT dédié à la mesure des primates non humains anesthésiés.

- a heterogeneous distribution of activity consistent with the measurement by photon spectrometry of the pulmonary lobes of the euthanized baboon (Fig. 1b).

$>$ The homogeneous source was defined by an arbitrary value of total alpha activity of $120 \mathrm{kBq}$ uniformly distributed in the whole volume of the lungs and of isotopic composition similar to the MOX: $114 \mathrm{kBq}$ of ${ }^{238} \mathrm{Pu}, 1.3 \mathrm{kBq}$ of ${ }^{239} \mathrm{Pu}, 2.2 \mathrm{kBq}$ of ${ }^{240} \mathrm{Pu}$ and $2.3 \mathrm{kBq}$ of ${ }^{241} \mathrm{Am}$.

$>$ The heterogeneous source was defined by the heterogeneous distribution of the same total activity $(120 \mathrm{kBq})$, with the same isotopic composition, in the lobes consistently with the proportions between the measured activities displayed in Table II. E.g., $45 \%$ of $120 \mathrm{kBq}$ were thus uniformly distributed in the left inferior lobe.

\subsubsection{Simulations of in vivo measurement}

For in vivo measurement of non human primates, the LRT uses a counting system made of two germanium detectors (ORTEC) of diameter $7.5 \mathrm{~cm}$. These detectors are set on each side of the thoracic cage as shown in Figure 5.

Since the numerical model of this counting system was not validated yet, the model of counting system of the LEDI, also made of two germanium detectors, was used. The representation of the counting geometry is presented in Figure 6. 


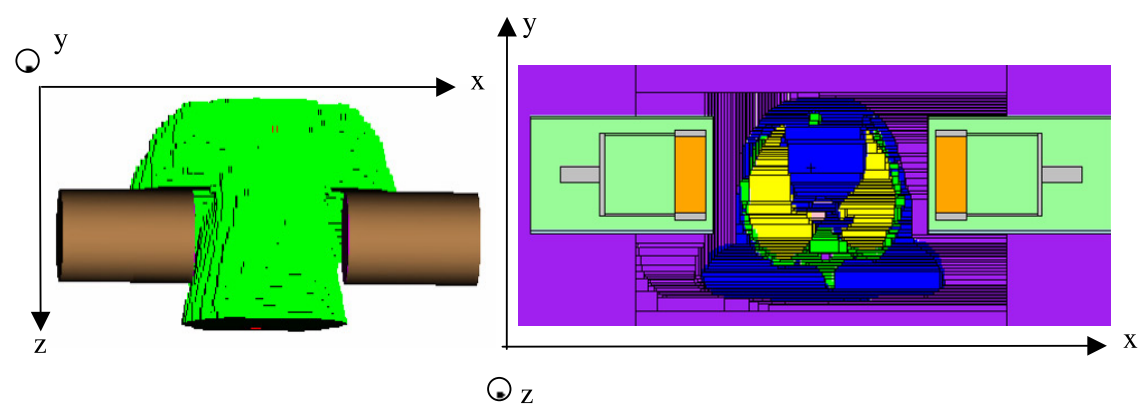

Figure 6 - Visualization by Sabrina ${ }^{\oplus}$ (left) and MCNP plotter (right, axial slice through the middle of the detectors) of the setting of the two germanium detectors along the baboon numerical phantom. Visualisation par Sabrina ${ }^{\circledR}$ (à gauche) et par le traceur de MCNP (à droite, coupe axiale le long de l'axe des détecteurs) du positionnement des deux détecteurs germanium par rapport au fantôme numérique du babouin.

\subsection{Results of the numerical comparison and discussion}

The numerical simulations were performed using a COMPAQ ${ }^{\odot}$ ES40 workstation with four $833 \mathrm{MHz}$ processors. The computer time ranged from 8 to 16 hours per calculation.

The results of the simulation of the measurements of the homogeneous and heterogeneous sources were compared by calculating the ratios of the counts in the regions of interest of the energy spectrum as presented in Table III.

These ratios appear significantly different from 1 but display different trends in the left and in the right detectors. These differences are obviously due to the distribution of activity within the lungs. Moreover, the expected difference between a real experimental measurement of a heterogeneously deposited activity in the lung and the measurement of a homogeneous lung source should presumably be more important, since the heterogeneous contamination was modelled by a homogeneous contamination within each lobe with different activity from one lobe to another; while the experimental distribution of the contamination was heterogeneous within the lobes of the baboon. However, this heterogeneity within the lobes themselves could not be taken into account for lack of possible consistent segmentation of the voxel phantom. As the contamination was deposited rather in the external part of the lobes (Fig. 1b), a heterogeneous contamination might be simulated in the future by assuming a higher mass activity on the surface of the lobes.

Nevertheless, if major differences appear between the simulated measurements of homogeneous and heterogeneous sources by each detector, these differences offset each other when the counts of the two detectors are added. So at $17 \mathrm{keV}$, 


\section{TABLE III}

Comparison of the results of simulated lung measurements by two germanium detectors. The results of this comparison are expressed as the ratio of the counting of a heterogeneous source by the counting of a homogeneous source of the same total activity (see text). Uncertainties are given as one standard deviation. The results associated with the 17 and $21 \mathrm{keV} X$-rays correspond to the integral of the counts over the areas $15-19 \mathrm{keV}$ and $19-23 \mathrm{keV}$ respectively. For the two $\gamma$-rays, the results correspond to the integral of the counts under the photoelectric peaks.

Comparaison des simulations des mesures pulmonaires avec les deux détecteurs germanium. Les résultats de cette comparaison sont exprimés à l'aide du rapport du comptage d'une source hétérogène par le comptage d'une source homogène de même activité totale (voir texte). Les incertitudes correspondent à l'écart type. Les résultats associés aux raies $\mathrm{X}$ de 17 et $21 \mathrm{keV}$ correspondent à l'intégrale des coups sur les gammes d'énergie 15-19 keV et 19-23 keV respectivement. Pour les deux raies gamma, les résultats correspondent à l'intégrale des coups sous les pics photoélectriques.

\begin{tabular}{ccccccc}
\hline \multirow{2}{*}{ Energy } & \multicolumn{2}{c}{ Right detector } & \multicolumn{2}{c}{ Left detector } & \multicolumn{2}{c}{ Sum Left + Right } \\
\cline { 2 - 6 } & Ratio & Uncertainty & Ratio & Uncertainty & Ratio & Uncertainty \\
\hline $17 \mathrm{keV}$ & 0.71 & $3.3 \%$ & 1.58 & $3.4 \%$ & 1.12 & $2.6 \%$ \\
$21 \mathrm{keV}$ & 0.52 & $4.8 \%$ & 1.49 & $4.9 \%$ & 0.94 & $3.6 \%$ \\
$26.35 \mathrm{keV}$ & 0.51 & $4.4 \%$ & 1.52 & $4.1 \%$ & 0.96 & $3.1 \%$ \\
$59.54 \mathrm{keV}$ & 0.62 & $0.6 \%$ & 1.42 & $0.5 \%$ & 1.03 & $0.4 \%$ \\
\hline
\end{tabular}

\section{$\mathrm{y}$}

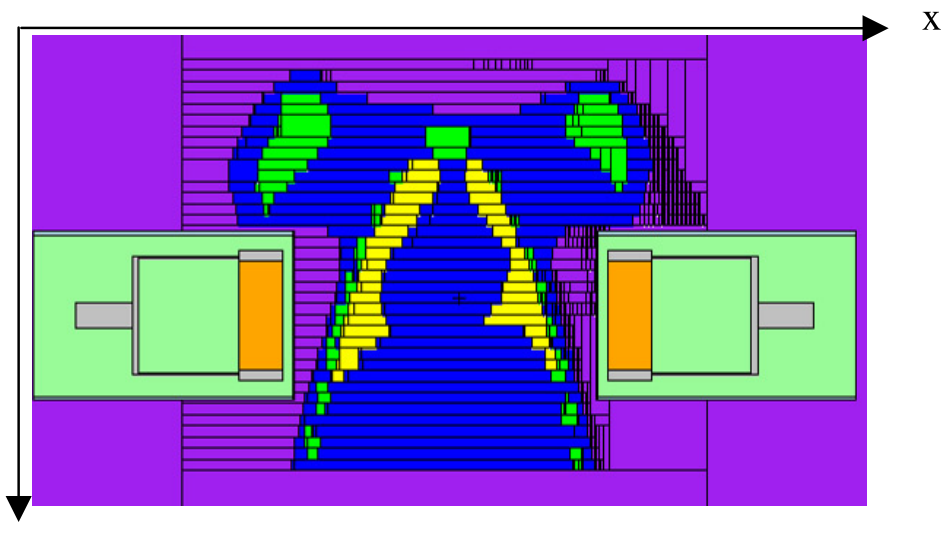

Figure 7 - Visualisation by MCNP plotter of a frontal slice of the baboon numerical phantom. Lungs are yellow, bones are green.

Visualisation par le traceur de MCNP d'une coupe frontale du fantôme numérique du babouin. Les poumons sont représentés en jaune, les os en vert. 
a difference of only $12 \%$ is observed between the measurements of the two sources. At higher energies, the observed difference between a heterogeneous and a homogeneous contamination is not significant for the sum of the counts of the two detectors (less than 5\%).

Overall, the results presented in Table III clearly show the influence of a realistic heterogeneous contamination as compared to a hypothetical homogeneous source on the lung in vivo measurement. As a consequence, these results show the likely magnitude of the errors made in the application of calibration factors derived from physical phantoms including a homogeneous pulmonary source.

\section{Conclusion and prospects}

In order to improve the calibration of in vivo measurement systems, a Graphical User Interface called CEDIPE was developed at the LEDI, using voxel phantoms, reconstructed from MRI or CT images, in association with the MCNP code. The goal of this work was to present a first application of CEDIPE to study the influence of the distribution of activity in lung on in the in vivo measurement. This study was conducted in two steps: an experimental part performed at the LRT and a numerical simulation using CEDIPE. The in vivo measurements of a contaminated baboon were simulated with a voxel phantom assuming either a homogeneous distribution of activity in the lungs or a heterogeneous distribution consistent with the experimental measurement of the pulmonary lobes, and the results were compared.

They show large discrepancies between the right and left detectors and depending on the assumption on the distribution of activity. Nevertheless, the sum of the countings from either detectors under one assumption or the other varied by less than $12 \%$.

The potential of voxel phantoms to study realistic contaminations in general appears clearly on this particular example of lung contamination. Thus, the uncertainty due to the heterogeneity of contaminations can be better assessed and the effect of a realistic heterogeneous contamination on the measurement can be studied in a way that would be impossible by an experimental approach. Further studies will be performed to confirm the possible extrapolation of the conclusions to human measurement despite the morphological differences in the thoracic cage and the physiological differences that exist between humans and other primates after incorporation of a material in the same physico-chemical form (Lataillade et al., 1995). 
Further developments will be focused on the influence of the biokinetics of the radionuclides on the in vivo measurement. To do so, the biokinetic models of the International Commission on Radiological Protection (ICRP) will be used in OEDIPE to simulate the change of the heterogeneous distribution of activity with time in voxel phantoms. Thereby the response of the detectors to a dynamic heterogeneous source modelling the change in the distribution of the retained activity with time will be studied.

\section{REFERENCES}

Aubineau-Laniece I., de Carlan L., Clairand I., Lemosquet A., Chiavassa S., Pierrat N., Bardies M., Franck D. (2005a) Current developments at IRSN on computational tools dedicated to assessing doses for both internal and external exposure, Radiat. Prot. Dosim. 115, 522-529.

Aubineau-Laniece I., de Carlan L., Pierrat N., Franck D., Chiavassa S., Bardies M. (2005b) Application of voxel phantoms for internal dosimetry at IRSN using a dedicated computational tool. In: Monte Carlo 2005 Topical Meeting, Chattanooga, TN.

Borisov N., Franck D., de Carlan L., Laval L. (2002) A new graphical user interface for fast construction of computation phantoms and MCNP calculations: application to calibration of in vivo measurement systems, Health Phys. 83, 272-279.

Borisov N., Franck D., De Carlan L., Pierrat N., Kochetkov O., Yatsenko V. (2005) A new facility for MCNP application in whole body counting and internal dosimetry. In: Monte Carlo 2005 Topical Meeting, Chattanooga, TN.

Briesmeister J.F. (2000) MCNPTM - A general Monte-Carlo N-Particle transport code, version 4c, LANL memorandom, Los Alamos National Laboratory, LA-13709-M.

de Carlan L. (2004) Potential of new imaging and calculation techniques for the activity and dose assessment in case of localized contamination. In: IRPA 2004, Madrid.

de Carlan L., Roch P., Blanchardon E., Franck D. (2005) New method of voxel phantom creation: application for whole-body counting calibration and perspectives in individual internal dose assessment, Radiat. Prot. Dosim. 116, 160-164.

Franck D., Laval L., Borissov N., Guillierme P., Bordy J.M. (2001) Development of voxelised phantoms using MCNP Monte Carlo code: Application to in vivo measurement, Radioprotection 36, 77-86.

Hickman D.P., Firpo M. (1997) Magnetic resonance image phantom program, Lawrence Livermore National Laboratory, Livermore, CA.

Hughes H.G., Prael R.E., Little R.C. (1997) MCNPX the LAHET/MCNP Code Merger, XTM-RN(U), 97-012.

ICRU (1989) Report 44, Tissue Substitutes in Radiation Dosimetry and Measurement, Bethesda.

Ishikawa T., Uchiyama M. (1997) Calculation of Counting Efficiency for 137Cs Using Voxel Phantoms with Lungs and a Skeleton, Radiat. Prot. Dosim. 69, 199-204.

Lataillade G., Verry M., Rateau G., Metivier H., Masse R. (1995) Translocation of plutonium from rat and monkey lung after inhalation of industrial plutonium oxide and mixed uranium and plutonium oxide, Intern. J. Rad. Biol. 67, 373-380.

Mallett M.W., Hickman D.P., Kruchten D.A., Poston J.W. Jr. (1995) Development of a method for calibrating in vivo measurement systems using magnetic resonance imaging and Monte Carlo computations, Health Phys. 68, 773-785.

Pierrat N., De Carlan L., Cavadore D., Franck D. (2005) Application of monte carlo calculation for the virtual calibration of a low-energy in vivo counting system, IEEE Trans. Nucl. Sci. 52, 1353-1358.

Prot N. (1994) Anatomie systématique et topographique de la cavité thoracique du macaque cynomolgus, Thèse vétérinaire, Université Claude Bernard (Ecole Vétérinaire), Lyon. 